\title{
Mucosal Defense Mechanism and Secretory IgA System
}

\author{
Hiroshi NAGURA \\ Department of Pathology, Tohoku University School of Medicine, Sendai, 980
}

(Received for publication, September 4, 1989)

Key words: mucosal immune system; sIgA; intestinal microbe; intestine; liver

It has been generally accepted that secretory $\operatorname{IgA}(\operatorname{sIgA})$ is the major immunoglobulin in external body fluids of mammals. The mucosal surface is exposed to a myriad of antigenic substances, such as microbes and food; the sIgA provides an immunological barrier to foreign matter by preventing both absorption of these antigens by the mucosal epithelium and penetration into the body, and interferes in the attachment of microbes and their toxins to the epithelium $(29,30)$. On the other hand, intestine and respiratory tracts are richly populated lymphoid tissues, and contact between antigens on the mucosal surface and the mucosal lymphoid tissues initiates a diverse series of immunologic events. These include the production of immunoglobulins of IgA class that are secreted into extracellular body fluids and, in striking contrast, induce hyporesponsiveness of certain nonmucosal immunologic reactions $(25,27)$, whereas the humoral immune responses in the nonmucosal sites are largely of the IgG class. The cell-mediated immune mechanism is also distinctive in mucosal and nonmucosal lymphoid tissues. It is of interest to notice that the study of germfree mice and rats, which lack indigenous microbial flora, reveals the scarcity of secondary lymphoid follicles of the lymphoid tissue and of plasma cells and lymphocytes in the lamina propria of villi $(6,21)$. It has recently been recognized that the immune system at the mucosal sites plays an important role in the host-environment interaction $(2,21)$. In this review I summarized the recent information about immune responses in the intestinal mucosa, with emphasis on the role of microbial environments.

\section{IMMUNE RESPONSES TO INTESTINAL MICROBES}

Immune responses to microorganisms and their exogenous toxins as well as a wide variety of dietary substances and their breakdown products take place both in organized gut-associated lymphoid tissue (GALT) and in glandular parts of the mucosa. It has been well documented that morphologic alterations and distribution of immunologically competent cells in GALT are correlated with the response 
to orally presented antigen. The study of germfree mice and rats reveals that the exposure of the adult animal to microorganisms resulted in prompt and potent immune responses, which are first observed in the intestinal mucosa $(6,21)$. There is abundant literature on the scantiness of germinal centers in lymphoid follicles and of immunocytes in the intestine of germfree animals $(6,21)$. It is also of interest to notice their hypogammaglobulinemia. By the end of the third week of conventionalization, these animals have the structure and immunocyte distribution in the intestinal mucosa that resemble those of adult conventional animals $(6,10,21)$. This suggests that germfree animals are able to respond to external microbial antigens by developing GALT with a potency and a rapidity at least equal to those of conventional animals. In man, artificial intestinal colonization of infants with a nonenteropathogenic strain of Escherichia coli has been found to enhance the formation of IgA in the gut (13). There is generally agreement that, although the presence of considerable numbers of lymphocytes and plasma cells in the lamina propria of the intestine is regarded as normal, these cells increase in number after antigenic trauma and infectious diseases $(1,2,9)$. For example, in inflammatory bowel diseases, such as ulcerative colitis and Crohn's disease, there is an increased number of these mononuclear cells.

\section{PROPERTIES OF SECRETORY IgA (sIgA)}

Nearly 25 years ago, Tomasi and his colleagues (28) reported mucosal surfaces predominantly contained $\operatorname{IgA}$, which was different from $\operatorname{IgA}$ in serum in molecular size and contained additional antigenic components. The $\operatorname{IgA}$ in the external secretions consists of two molecules of IgA linked by J chain (dimeric IgA) in complex with secretory component (SC) $(2,21)$. Interestingly, these components of $\operatorname{IgA}$ in external secretions (secretory $\operatorname{IgA}, \mathrm{sIgA}$ ) are derived from two different types of cells, such as plasma cells in the lamina propria and glandular epithelial cells of the intestinal mucosa. On the contrary, the majority of circulating $\operatorname{IgA}$ is in the monomeric form particularly in man $(2,21)$. J chain is synthesized in the same plasma cells that produce the dimeric IgA (16). Thus, $\mathrm{J}$ chain is involved and is probably necessary for dimer formation in the plasma cell. It has been clearly established by the immunocytochemical technique that complexing of $\mathrm{J}$ chain with the monomeric units of chain to the dimer occurs prior to secretion (16). J chain lends a conformation to IgA which is required for nonconvalently complexing with $\mathrm{SC}(2)$. Furthermore, there are two subclasses of human $\operatorname{IgA}: \operatorname{IgA1}$ and $\operatorname{IgA} 2(14)$. It is generally accepted that IgAl dominates in serum, whereas approximately equal amounts of $\operatorname{IgA} 1$ and IgA2 are found in external secretions. The IgA2 subclass differs from IgAl in the absence of a 13 amino acid-proline-rich peptide which is the site of cleavage by IgA proteases (24). IgA proteases are known to be virulence factors produced by a variety of bacteria on the mucosal sites. SC is synthesized as a transmembrane glycoprotein (15) by the epithelial cells of all external-secreting organs, such as intestine, breast, lung, salivary gland, etc. The SC portion of the sIgA 
molecule serves to protect the IgA in the protease-rich external environments. Serum and sIgA are compared in Table 1.

\section{TRANSEPITHELIAL TRANSLOCATION OF IgA INTO EXTERNAL FLUIDS}

Immunohistochemical studies of the intestinal tract and other tissues revealed large numbers of IgA plasma cells in the lamina propria in close anatomical relationship to the mucosal surface of secreting organs. Epithelial cells of these organs synthesize SC, and SC is expressed in a polar fashion on the basolateral surface of the

Table 1. Properties of IgA

\begin{tabular}{lll}
\hline & Serum IgA & Secretory $\operatorname{IgA}$ \\
\hline Constituent & $\alpha_{2} \mathrm{~L}_{2}$ & $\left(\alpha_{2} \mathrm{~L}_{2}\right)_{2} \cdot \mathrm{J} \cdot \mathrm{SC}$ \\
Subclass & $\operatorname{IgA} 1>\operatorname{IgA} 2$ & $\operatorname{IgA} 1 \fallingdotseq \operatorname{IgA} 2$ \\
Molecular weight & 16,000 & 385,000 \\
Sedimentation coefficient & $7 \mathrm{~s}$ & $11 \mathrm{~s}$ \\
Distribution & secretions & serum \\
\hline
\end{tabular}

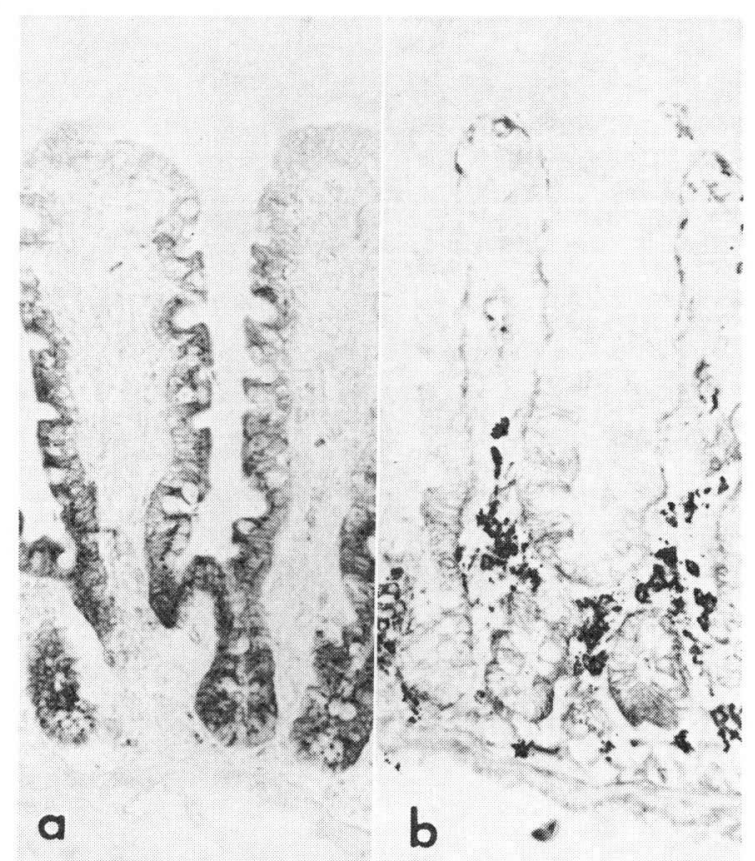

Fig. 1. Immunohistochemical localization of SC (a) and $\operatorname{IgA}(b)$ in the human small intestine (21). Immunostaining for SC is most prominent in the crypt epithelial cells. There are numerous IgA plasma cells in the lamina propria, and IgA-staining is also prominent in the epithelial cells in the crypt along the basolateral surfaces. 


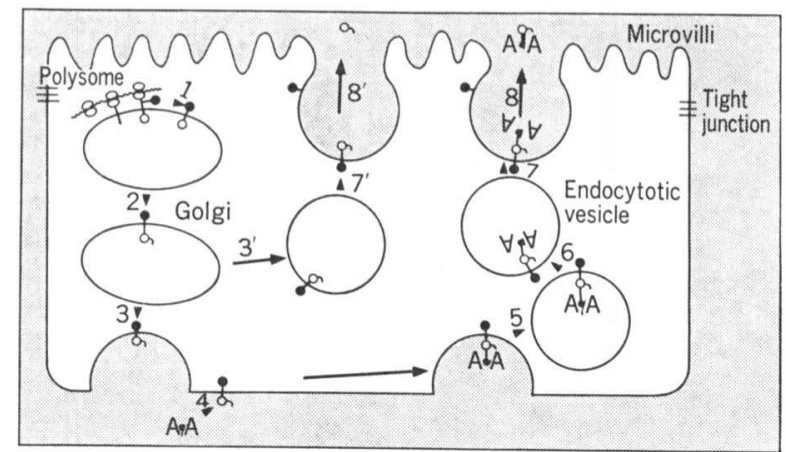

Fig. 2. A schematic illustration of the SC-mediated IgA transepithelial pathway according to our (19) and Mostov's (15) hypotheses. See text. O, SC; ○- , transmembrane precursor of $\mathrm{SC} ; \boldsymbol{\bullet}$, transport protein.

cells, where it is available to bind dimeric IgA. The route taken by the $\operatorname{IgA}$ across the epithelium has been examined repeatedly by immunohistochemical techniques (Fig. 1) (3, 19). The SC-dimeric IgA complex on the plasma membrane, then, undergoes endocytosis, and is transported across the cell to the gland lumen by a microtubule-dependent vesicular transport mechanism and exocytosed at the apical surface into the external environment. More recently, Mostov and colleagues (15) reported that $\mathrm{SC}$ is not synthesized as a secreted glycoprotein but as a much larger transmembrane precursor, and is the proteolytically cleaved extracellular ligand binding domain of the dimeric IgA receptor when $\operatorname{IgA}$ is released into the gland lumen. See Fig. 2 for a summary diagram of the IgA transepithelial pathway.

\section{MUCOSAL DEFENSE MECHANISM IN THE NEONATE}

In the early days of life, neither IgA plasma cells in the lamina propria nor IgA in serum can be detected. From the onset of suckling to some time between the 18th and 21 st day of life in the rat, enterocytes in the proximal small intestine selectively bind colostral IgA to their villous surface (18). Studies of the antibodies in breast milk have shown secretory IgA antibodies against various microbial agents, including viruses and bacteria, and food proteins such as cow's milk (7). It is probable that these sIgA antibodies on the surface of proximal enterocytes play important roles in the defense of the breast-fed baby against diarrheal infections and allergic diseases.

IgG is the class of antibodies in breast milk to be transported intact to the offspring circulation across the enterocytes $(7,8)$. The transfer of IgG, however, is sharply limited to the first 18 to 21 days of life in the rat, when colostral sIgA binds to the villous surface. In contrast, colostral IgG is found in the lower portion of microvilli and apical plasma membranes of proximal enterocytes of breast-fed neonatal rats. Then the IgG is internalized, transported through the cells in cytoplasmic vesicles, and exocytosed into the lamina propria and transferred into the circulation 


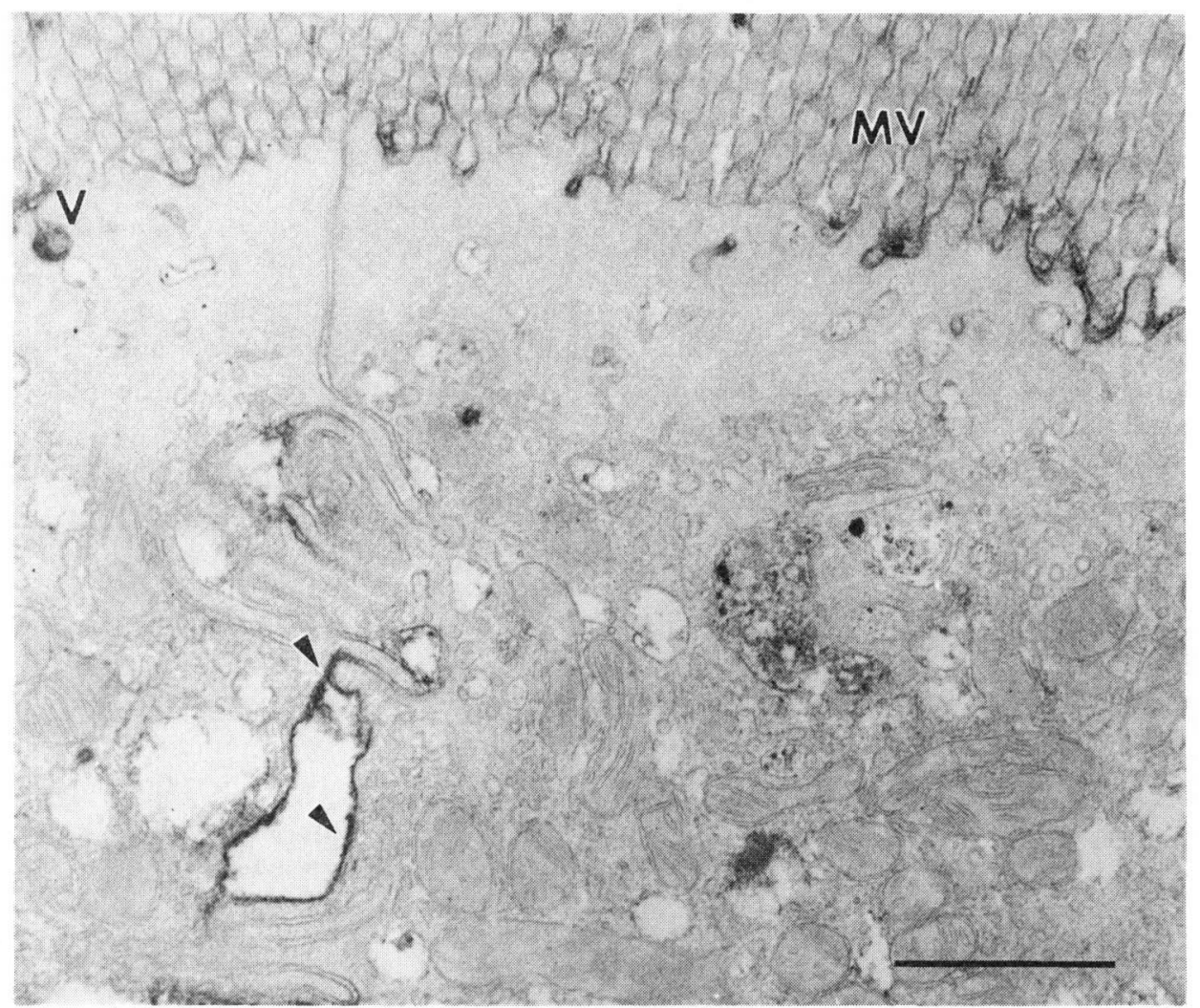

Fig. 3. Immunoelectron microscopic localization of IgG in the proximal small intestine of breast-fed neonatal rats. IgG is found in the lower portion of microvilli (MV) and apical and lateral plasma membranes $(-$ ) of the absorptive cells. Pinocytic invaginations and vesicles $(\mathrm{V})$ along the apical plasma membranes are frequent.

(Fig. 3). Such large quantities of the maternal IgG in the circulation may provide passive systemic immunity for the neonates.

\section{REGULATORY FUNCTION OF THE LIVER IN THE MUCOSAL IMMUNE RESPONSES}

IgA is the major immunoglobulin of the bile, and, clinically, relationships between IgA and liver disease have long been a subject of interest. During the past 12 years, after the demonstration of sIgA in the rat bile by a group of Belgian scientists (12), a great deal of experimental and clinical evidence has shown that the liver is much involved in the sIgA system as shown in the gastrointestinal tracts. It is well documented in the recent review article (4) that two major biological roles exist in the secretion of IgA antibodies into bile: 1) enhanced immunological protection of 
the biliary and upper gastrointestinal tract; 2) the clearance of harmful antigens from the circulation in the form of IgA-antigen complexes.

In rats, immunohistochemical studies have documented that biliary $\operatorname{sig} \mathrm{A}$ is transported through hepatocytes from circulation by the SC-mediated mechanism (26). In man, however, we found that the translocation of $\mathrm{sIgA}$ in the liver occurs only across biliary epithelial cells: only these cells, not hepatocytes, synthesize SC (20). In addition, it has been shown that the liver can also function in the removal of antigen from the circulation in the form of dimeric IgA-immune complexes as the same mechanism as that of free dimeric $\operatorname{IgA}(23)$. This is a unique, noninflammatory mechanism for the disposal of antigen distinct from the phagocytemediated mechanism to clear immune complexes in the circulation. The hepatic sinusoidal phagocytes, Kupffer cells, and endothelial cells in part, take up the intestinally derived antigens and immune complexes (5). The biliary secretion of dimeric IgA in man may, in part, involve hepatic receptors other than SC, particularly asialoglycoprotein receptor (ASGPR) with which the IgA interacts (4). Although the amount of IgA which is translocated through hepatocytes and secreted into bile via this route is probably minimal in man, the role of ASGPR in biliary secretion of IgA remains to be clarified.

Disruption of the hepatobiliary transport of sIgA and sIgA-immune complexes may be implicated in the pathogenesis of several human diseases. IgA is often deposited in the liver of patients with liver diseases, chronic active hepatitis, and cirrhosis (22), and in the kidneys of some of these diseases. The IgAl subclass dominates this deposited IgA along the sinusoidal wall and renal mesangial area, suggesting the alteration in IgAl metabolism related to ASGPR in the liver. The relationship between the liver and enteric IgA and IgA-immune complex is schematically depicted in Fig. 4.

Recently the author showed that the hepatic sinusoidal endothelial cells carry antigens with a peripheral blood macrophage subset capable of presenting soluble antigens and triggering autologous mixed lymphocyte reactions (17). Kupffer cells are also known to constitute a group of Ia antigen-positive macrophages, and to be responsible for the uptake of circulating antigens and immune complexes. These facts suggest that these sinusoidal cells may play an important role in immune responses or regulations in the liver, and the failure by the sinusoidal cells as well as the sIgA system in the liver, which clear enteric antigens and immune complexes formed in the blood circulation, could result in immune-mediated diseases $(4,21)$. Thus, the liver is an integral part of the mucosal immune system (11) and plays an important role in the physiology of IgA in normal and disease states.

\section{CONCLUDING REMARKS}

It has recently been recognized that IgA and the mucosal immune system play an important role in the host-environment interaction and in the pathogenesis of certain diseases of mucosal and nonmucosal tissues. First, I presented a brief overview of the secretory IgA immune system, then discussed the possible immuno- 


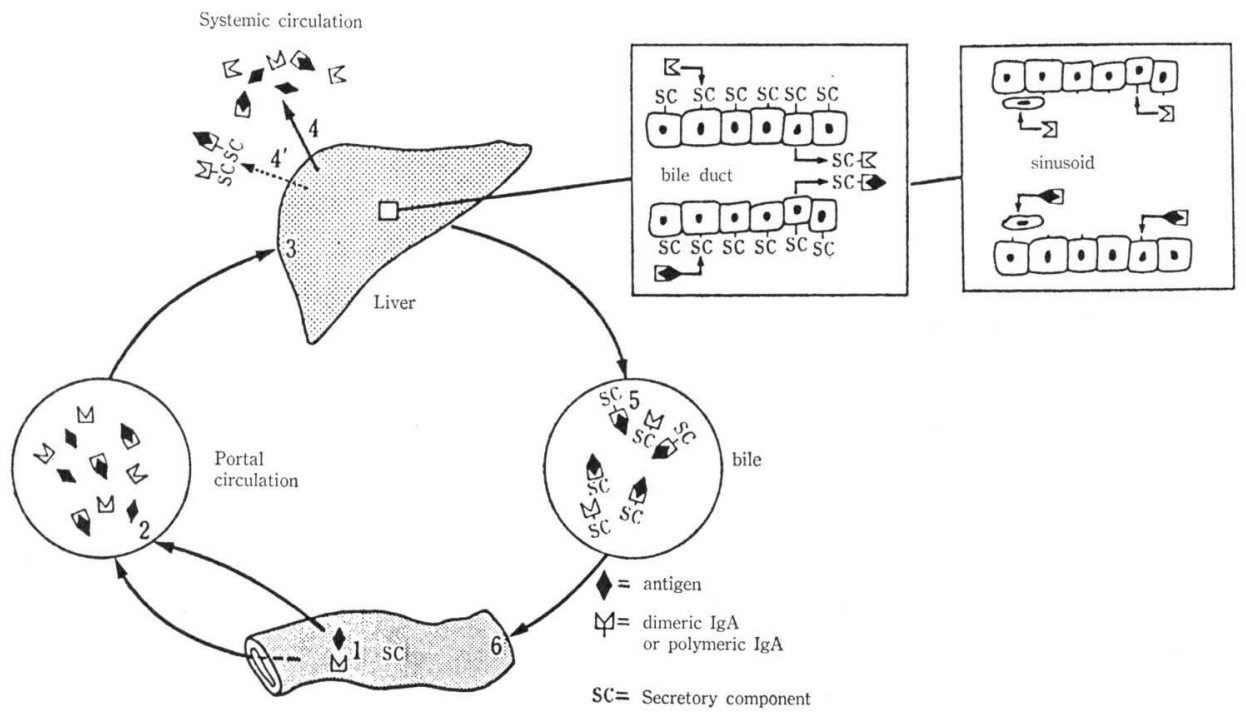

Fig. 4. A schematic illustration of the relationship between IgA and liver (21). Dimeric $\operatorname{IgA}(\mathrm{dIgA})$ synthesized by plasma cells in the intestinal lamina propria and antigens accidentally absorbed by the intestinal mucosa (1) are transported to the liver via portal circulation. These antigens complex to $\operatorname{dIgA}(\mathrm{dIgA}-\mathrm{IC})$ in the portal circulation (2). In liver both IgA and IgA-IC bind to SC on the plasma membrane of biliary epithelial cells to form IgA and sIgA-IC, followed by SC-mediated transepithelial pathway. Parts of dIgA and dIgA-IC bind to the plasma membrane of Kupffer cells, hepatocytes, and endothelial cells, and are uptaken (3). Then sIgA and sIgA-IC are released into bile (5). In hepatic disorder, some $\operatorname{dIgA}$ and $\mathrm{dIgA-IC}$, and also sIgA and sIgA-IC enter the systemic circulation (4), (4)'.

logical significance of the liver. Gut-associated lymphoid tissue, cellular part of the mucosal immune system, has been well documented in review articles by the author and others $(2,21)$.

Acknowledgments. This research was supported in part by a Research Grant from the Ministry of Education, Science and Culture (No. 01636504).

\section{REFERENCES}

(1) Baklien, K., and P. Brandtzaeg. 1975. Comparative mapping of the local distribution of immunoglobulin-containing cells in ulcerative colitis and Crohn's disease of the colon. Clin. Exp. Immunol. 22: 197-209.

(2) Brandtzaeg, P., K. Baklien, K. Bjerke, T.O. Rognum, H. Scott, and K. Valnes. 1987. Nature and properties of the human gastrointestinal immune system, p. 1-85. In K. Miller, and S. Nicklin (eds.), Immunology of the gastrointestinal tract. Vol. 1, CRC Press, Boca Raton.

(3) Brown, W.R., Y. Isobe, and P.K. Nakane. 1976. Studies on the translocation of immunoglobulins across intestinal epithelium. II. Immunoelectron microscopic localization of immunoglobulins and secretory component in human intestinal mucosa. Gastroenterology $\mathbf{7 1}$ : 985-995. 
(4) Brown, W.R., and T.M. Kloppel. 1989. The liver and IgA: Immunological, cell biological and clinical implications. Hepatology 9: 763-784.

(5) Brown, T.A., M.W. Russell, and J. Mestecky. 1982. Hepatobiliary transport of IgA immune complexes: Molecular and cellular aspects. J. Immunol. 128: 2183-2186.

(6) Crabbé, P.A., D.R. Nash, H. Bazin, H. Eyssen, and J.F. Heremans. 1970. Immunohistochemical observations on lymphoid tissues from conventional and germfree mice. Lab. Invest. 22: 448-457.

(7) Hanson, L.Å., B. Carlsson, J.R. Cruz, B. Garcia, S.R. Khan, B.S. Lindblad, A.M. Svennerholm, and J. Vrrutia. 1979. Immune response in the mammary gland, p. 145-157. In P.L. Ogra, and D.H. Dayton (eds.), Immunology of breast milk. Raven Press, New York.

(8) Hasegawa, H., A. Nakamura, K. Watanabe, W.R. Brown, and H. Nagura. 1987. Intestinal uptake of IgG in suckling rats: Distribution between jejunal and ileal epithelial cells demonstrated by simultaneous ultrastructural localization of IgG and acid-phosphatase. Gastroenterology 92 : 186-191.

(9) Hirata, I., G. Berrebi, D.F. Keren, and W.O. Dobbins III. 1986. Immunohistological characterization of intraepithelial and lamina propria lymphocytes in control ileum and colon and inflammatory bowel disease. Dig. Dis. Sci. 31 : 593-603.

(10) Horsfall, D.J., J.M. Cooper, and D. Rowley. 1978. Changes in the immunoglobulin levels of the mouse gut and serum during conventionalization and following administration of Salmonella typhimurium. Aust. J. Exp. Biol. Med. Sci. 56: 727-735.

(11) Kleinman, R.E., P.R. Harmatz, and W.A. Walker. 1982. The liver: An integral part of the enteric mucosal immune system. Hepatology 2: 379-384.

(12) Lemaitré-Coelho, I., G.D.F. Jackson, and J.P. Vaerman. 1977. Bile as a convenient source of secretory IgA and free secretory component. Eur. J. Immunol. 8: 588-590.

(13) Lodinova, R., V. Jouja, and V. Wagner. 1978. Serum immunoglobulins and coproantibody formation in infants after intestinal colonization with Escherichia coli 083 and oral lysozyme administration. Pediat. Res. 7: 659-669.

(14) Mestecky, J., and M.W. Russell. 1986. IgA subclasses. Monogr. Allergy 19: 277-301.

(15) Mostov, K.E., J.P. Kraehenbuhl, and G. Blobel. 1980. Receptor-mediated transcellular transport of immunoglobulin: Synthesis of secretory component as multiple and layer transmembrane forms. Proc. Natl. Acad. Sci. USA 77: 7257-7261.

(16) Nagura, H., P. Brandtzaeg, P.K. Nakane, and W.R. Brown. 1979. Ultrastructural localization of $\mathrm{J}$ chain in human intestinal mucosa. J. Immunol. 123: 1044-1050.

(17) Nagura, H., T. Koshikawa, Y. Fukuda, and J. Asai. 1986. Hepatic vascular endothelial cells heterogenously express surface antigens associated with monocytes, macrophages and T lymphocytes. Virchows Arch. A. 409: 407-416.

(18) Nagura, H., P.K. Nakane, W.R. Brown. 1978. Breast milk IgA binds to jejunal epithelium in suckling rats. J. Immunol. 120: 1333-1339.

(19) Nagura, H., P.K. Nakane, and Brown, W.R. 1979. Translocation of dimeric IgA through neoplastic colon cells in vitro. J. Immunol. 123: 2359-2368.

(20) Nagura, H., P.D. Smith, P.K. Nakane, and W.R. Brown. 1981. IgA in human bile and liver. J. Immunol. 126: 587-595.

(21) Nagura, H., and Y. Sumi. 1988. Immunological functions of the gut-Role of the mucosal immune system. Toxicol. Pathol. 16: 154-164.

(22) Nagura, H., Y. Sumi, Y. Fukuda, H. Hasegawa, K. Watanabe, and W.R. Brown. 1989. Studies on the relationships of IgA to hurnan liver. IgA deposition in non-alcoholic liver diseases. Acta Pathol. Jpn. 39: 363-372.

(23) Peppard, J., E. Orlans, A.W.R. Payne, and E. Andrew. 1981. The elimination of circulating complexes containing polymeric IgA by excretion in the bile. Immunology 42: 83-89.

(24) Plant, A.G. 1987. Microbial IgA proteases. N. Engl. J. Med. 298: 1459-1463.

(25) Stokes, C.R. 1984. Induction and control of intestinal immune responses, p. 97-141. In T.J. Newby, and C.R. Stokes (eds.), Local immune responses of the gut, CRC Press, Boca Raton.

(26) Takahashi, I., P.K. Nakane, and W.R. Brown. 1982. Ultrastructural events in the translocation of polymeric IgA by rat hepatocytes. J. Immunol. 123: 1181-1187. 
(27) Tomasi, T.B., and A.G. Plant. 1985. Humoral aspects of mucosal immunity, p. 31-61. In Advances in host defense mechanisms, Vol. 4, Raven Press, New York.

(28) Tomasi T.B., Jr., E.M. Tan, A. Solomon, and R.A. Prendergast. 1965. Characteristics of an immune system common to certain external secretions. J. Exp. Med. 121 : 101-124.

(29) Walker, W.A., M. Mu, and K.J. Isselbacher. 1975. Intestinal uptake of macromolecules. III. Studies on the mechanism by which immunization interferes with antigen uptake. J. Immunol. 115: 854-861.

(30) Williams, R.C., and R.J. Gibbons. 1972. Inhibition of bacterial adherence of sIgA-A mechanism of antigen disposal. Science 177: 697-699. 